(c) American Dairy Science Association, 2004.

\title{
Growth Responses of Escherichia coli to Immunoglobulin G from Cows Immunized with Ferric Citrate Receptor, FecA ${ }^{1}$
}

K. Takemura, J. S. Hogan, and K. L. Smith

Department of Animal Sciences, The Ohio State University,

Ohio Agricultural Research and Development Center, Wooster 44691

\begin{abstract}
Effects of purified immunoglobulin (Ig) $\mathrm{G}$ from cows immunized with ferric citrate receptor, FecA, on the in vitro growth of Escherichia coli were investigated. Twenty-one cows were assigned to one of 3 treatments: 1) FecA immunization, 2) $E$. coli J5 bacterin immunization, and 3) unimmunized control. FecA was derived from $E$. coli UT5600/pSV66. Immunoglobulin G was purified from pooled colostral whey for each treatment group. The IgG from FecA immunized cows had higher titers against FecA compared with other treatment groups. Bacterial isolates tested were $14 E$. coli from intramammary infections and E. coli UT5600/pSV66. Iron depletion decreased the growth of $E$. coli compared with growth in Fe-replete medium. The presence of IgG further decreased the growth compared with the growth under iron restriction alone. Bacterial growth did not differ among IgG sources nor between IgG concentrations. Replenishing media with exogenous iron overrode the inhibitory effects of the Fe-depletion and IgG. Vaccinating cows with FecA had little effect on the growth inhibitory properties of IgG toward E. coli mastitis isolates cultured in Fe-deplete media.
\end{abstract}

(Key words: FecA, immunoglobulin, Escherichia coli)

\section{INTRODUCTION}

Under Fe-restricted conditions, bacteria utilize multiple iron transport systems that involve the expression of outer membrane iron receptors that bind to and internalize iron complexes (Braun et al., 1998). The expression of outer membrane iron receptors of Escherichia coli during IMI has also been suggested (Todhunter et al., 1991a). Escherichia coli isolates from cases of naturally occurring mastitis commonly expressed outer membrane iron receptors, FepA (Lin et al., 1998b) and

Received July 23, 2003.

Accepted September 9, 2003.

Corresponding author: J. S. Hogan; e-mail: Hogan.4@osu.edu.

${ }^{1}$ Salaries and research support were provided by State and Federal funds appropriated to the Ohio Agricultural Research and Development Center, The Ohio State University. Manuscript no. 3-04AS.
FecA (Lin et al., 1999b), under Fe-restricted conditions. FepA is the receptor for the enterobactin-based iron transport system, and FecA is for the ferric citrate transport system (Braun et al., 1998). The ferric citrate transport system is the only iron transport system of $E$. coli induced when the microbial environment contains more than $0.1 \mathrm{~m} M$ citrate (Hussein et al., 1981). Lin et al. (1999a, 1999b) suggested that in bovine mammary glands, E. coli may rely on FepA and an enterobactin-based system to acquire iron during the nonlactating period when most iron is bound to lactoferrin, and FecA and the ferric citrate transport system during the lactating period when sufficient citrate exists in the secretions for the induction of the system.

Bacterial outer membrane receptors are vaccine candidates because they are exposed on the bacterial surface and may induce protective immunity against infections (Weinberg, 1995; Byers and Arceneaux, 1998). FepA (Lin et al., 1998a) and FecA (Takemura et al., 2002) were immunogenic in cows, and these were antigenically distinct proteins (Lin et al., 1999b). A previous study to determine efficacy of FecA immunization in cows revealed that increased antibody titers against FecA in serum were associated with decreased $E$. coli numbers in milk from infected mammary glands (Takemura et al., 2002). FecA is the receptor of $E$. coli to acquire iron through the ferric citrate transport system, and purified IgG from cows immunized with FecA decreased iron uptake of $E$. coli (Takemura et al., 2003). Monoclonal antibodies directed against FepA also decreased iron uptake of $E$. coli (Murphy et al., 1990). When $E$. coli was cultured in the presence of purified IgG from FepA immunized cows, the growth of $E$. coli was reduced (Lin et al., 1999a). The authors concluded that the growth reduction was due to the inhibitory effect of anti-FepA antibodies against bacterial iron acquisition (Lin et al., 1999a). The objective of the current study was to investigate effects of purified IgG from FecA immunized cows on in vitro growth of $E$. coli isolates from cases of naturally occurring mastitis.

\section{MATERIALS AND METHODS}

\section{Immunization}

Vaccine preparation and immunization schedule was as previously described (Takemura et al., 2002). 
Twenty-one cows were assigned to one of 3 treatments: 1) FecA immunization, 2) $E$. coli J5 bacterin immunization, and 3) unimmunized control. Cows were immunized 3 times: 1) subcutaneous injection at $14 \mathrm{~d}$ prior to the end of lactation, 2) intramammary infusion at 7 $\mathrm{d}$ after the end of lactation, and 3) subcutaneous injection at $28 \mathrm{~d}$ after the end of lactation. FecA was derived from $E$. coli UT5600/pSV66 grown in a Fe-depleted medium containing $1 \mathrm{~m} M$ citrate (Lin et al., 1999b). The FecA vaccine consisted of $400 \mu \mathrm{g}$ in $5 \mathrm{~mL}$ of PBS and was emulsified in $5 \mathrm{~mL}$ of Freund's incomplete adjuvant (Difco Laboratories, Detroit, MI). Escherichia coli J5 bacterin consisted of $10^{9}$ killed $E$. coli $\mathrm{J} 5$ cells $/ \mathrm{mL}$ ( $E$ sch erichia coli Bacterin J5 Strain, Pharmacia and Upjohn, Kalamazoo, MI). Five milliliters of $E$. coli J5 vaccine was injected for the subcutaneous immunization as suggested by the manufacture.

\section{Immunoglobulin Purification}

Immunoglobulin G was purified by Protein G affinity chromatography (Lin et al., 1999a) from pooled colostral whey for each treatment group. Colostrum was collected from each cow within $12 \mathrm{~h}$ after the parturition. The concentration of purified IgG was measured by bicinchonic acid protein assay (Pierce Chemical Co., Rockford, IL). The purity of IgG was determined by SDS-PAGE with the control of commercially purified bovine IgG (Sigma Chemical Co., St. Louis, MO). Titers against FecA for purified IgG $(4 \mathrm{mg} / \mathrm{mL})$ were determined by ELISA as described previously (Takemura et al., 2002). The purified IgG was stored at $-20^{\circ} \mathrm{C}$ before use. All glassware was washed in $0.1 \mathrm{~N}$ concentrated nitric acid for $4 \mathrm{~h}$ and rinsed 3 times in distilled, deionized water.

\section{Bacterial Isolates}

Fourteen isolates of $E$. coli from naturally occurring cases of clinical mastitis and Escherichia coli UT5600/ pSV66 were tested. Thirteen isolates were from the Ohio Agricultural Research and Development Center dairy herd and characterized by Todhunter et al. (1991a). Five isolates were from IMI originating at calving, 4 from IMI originating during lactation, and 4 from IMI first diagnosed during the dry period. Geometric mean duration of IMI from which these 13 isolates originated was $11.9 \mathrm{~d}$ (range 1 to $62 \mathrm{~d}$ ). Characteristics of the clinical mastitis from which Escherichia coli 487 was isolated were described by McDonald and Anderson (1981). Escherichia coli UT5600/pSV66 (leu-, proC ${ }^{-}$, trp $E^{-}$, ent $A^{-}, r p s I^{-}, \Delta(o m p T-f e p A)^{-} / \mathrm{Cm}^{\mathrm{r}}$ fecIRA) is a transvected strain that expresses FecA, but not FepA (Lin et al., 1999b).

\section{Effects of IgG in Fe-Deplete Medium}

Before the assay, isolates were grown in a chemically defined synthetic medium (Bacto Synthetic Broth, Difco Laboratories, Detroit, MI) containing $200 \mu M \alpha$ - $\alpha^{\prime}$-dipyridyl and $1 \mathrm{~m} M$ citrate for $6 \mathrm{~h}$ at $37^{\circ} \mathrm{C}$ prior to the assay to induce FecA. The expression of FecA was confirmed for each $E$. coli isolate (data not shown) by SDSPAGE of outer membrane proteins followed by immunoblots (Lin et al., 1999b) with the primary antibody of $0.4 \mathrm{mg} / \mathrm{mL}$ of IgG from FecA immunized cows. After the FecA induction, $E$. coli cells were washed in PBS containing $200 \mu M \alpha$ - $\alpha^{\prime}$-dipyridyl and $1 \mathrm{~m} M$ citrate and diluted in the PBS to achieve approximately $10^{3} \mathrm{cfu} /$ $\mathrm{mL}$. Thirty microliters of bacterial suspension was mixed with $100 \mu \mathrm{L}$ of purified IgG at concentrations of 0,2 , and $4 \mathrm{mg} / \mathrm{mL}$.

The growth response assay was performed in 96 -well microtiter plates in Fe-replete and Fe-deplete media. The growth response assay culture consisted of 130 $\mu \mathrm{L}$ of bacteria and IgG mixture and $130 \mu \mathrm{L}$ of twiceconcentrated medium. The Fe-replete control medium was the chemically defined medium. The Fe-deplete medium was the chemically defined medium containing $200 \mu M \alpha$ - $\alpha^{\prime}$-dipyridyl and $1 \mathrm{~m} M$ citrate. At $0 \mathrm{~h}$ and after 6,12 , and $24 \mathrm{~h}$ of incubation, the cultures were serially diluted and spotted on MacConkey agar plates. The plates were incubated for $12 \mathrm{~h}$ at $37^{\circ} \mathrm{C}$. Bacterial colonies were counted and expressed as $\log _{10}$ colonyforming units per milliliter. The assay was in duplicate for $E$. coli mastitis isolates and repeated 6 times for $E$. coli UT5600/pSV66.

\section{Effects of IgG in Fe-Replenished Medium}

Mastitis isolates and E. coli UT5600/pSV66 were tested in Fe-deplete medium and Fe-deplete medium replenished with $50 \mu M \mathrm{FeCl}_{3}$ to determine whether exogenous iron would override the inhibitory effects of IgG on E. coli growth. Escherichia coli were cultured, prepared for assay, and enumerated as described above. Each of the 3 sources of IgG were tested in both Fedeplete and Fe-replenished media at $4 \mathrm{mg} / \mathrm{mL}$. Isolates cultured in Fe-replenished medium without IgG served as controls.

\section{Statistical Analysis}

Treatment differences among IgG sources, IgG concentrations, and iron availability were tested by least squares ANOVA using SAS (SAS, 1999). The least squares means for each treatment were used to make multiple comparisons by the general linear-model procedure using SAS (SAS, 1999). 


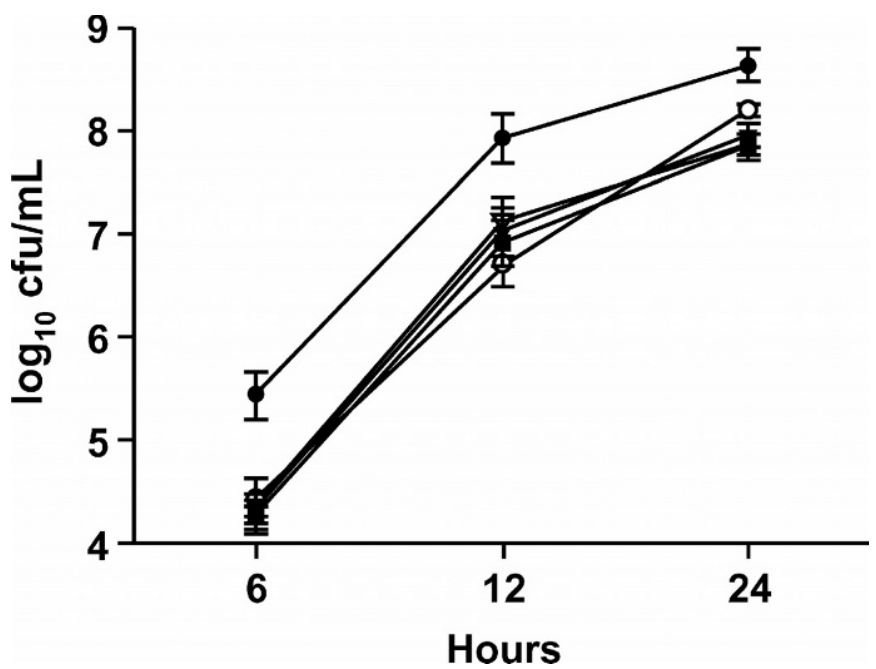

Figure 1. Mean colony-forming units $\left(\log _{10} \mathrm{cfu} / \mathrm{mL}\right)$ for Escherichia coli mastitis isolates $(\mathrm{n}=14)$ grown in chemically defined Fe-replete medium $(\bullet)$, Fe-deplete medium $(\bigcirc)$, Fe-deplete medium containing $4 \mathrm{mg} / \mathrm{mL}$ of anti-FecA IgG $(\boldsymbol{\nabla})$, Fe-deplete medium containing $4 \mathrm{mg} /$ $\mathrm{mL}$ of anti-E. coli J5 IgG $(\nabla)$, and Fe-deplete medium containing 4 $\mathrm{mg} / \mathrm{mL}$ of control IgG (ם). Dispersion bars represent standard error of the mean.

\section{RESULTS}

\section{Immunoglobulin G Titers Against FecA}

Immunoglobulin $\mathrm{G}$ titers against FecA were 1:3200 for anti-FecA IgG, 1:1024 for anti-J5 IgG, and 1:64 for control IgG. The concentration of IgG used for the assay was $4 \mathrm{mg} / \mathrm{mL}$ in PBS.

\section{Effects of IgG in Fe-Deplete Medium}

The growth of $E$. coli mastitis isolates after 6,12 , and $24 \mathrm{~h}$ of incubation was decreased $(P<0.05)$ in Fe-deplete medium compared with the growth in Fe-replete medium (Figure 1). The presence of IgG reduced bacterial growth after $24 \mathrm{~h}$ of incubation compared with the growth in Fe-deplete medium $(P<0.05)$. However, growth of $E$. coli mastitis pathogens did not differ among the sources nor concentrations of $\operatorname{IgG}(P>0.05)$.

Iron restriction reduced $(P<0.05)$ the growth of $E$. coli UT5600/pSV66 compared with the growth in Fereplete medium (Figure 2). When IgG was added to Fe-deplete medium, the growth was further decreased after 6,12 , and $24 \mathrm{~h}$ of incubation $(P<0.05)$. However, the growth did not differ among the sources nor between concentrations of IgG $(P>0.05)$.

\section{Effects of IgG in Fe-Replenished Medium}

Exogenous iron overrode the inhibitory effects of iron restriction in Fe-deplete medium and restored the

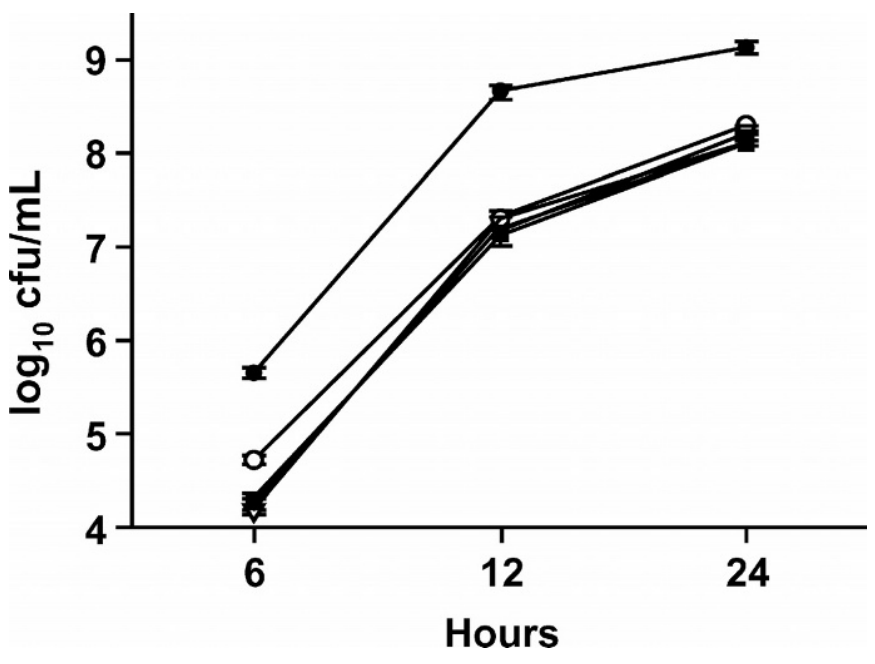

Figure 2. Mean colony-forming units $\left(\log _{10} \mathrm{cfu} / \mathrm{mL}\right)$ for Escherichia coli UT5600/pSV66 grown in chemically defined Fe-replete medium (๑), Fe-deplete medium (O), Fe-deplete medium containing $4 \mathrm{mg} / \mathrm{mL}$ of anti-FecA IgG $(\boldsymbol{\nabla})$, Fe-deplete medium containing $4 \mathrm{mg} / \mathrm{mL}$ of antiE. coli J5 IgG $(\nabla)$, and Fe-deplete medium containing $4 \mathrm{mg} / \mathrm{mL}$ of control IgG ( $)$. Dispersion bars represent standard error of the mean.

growth of $E$. coli mastitis isolates to the growth in Fereplete medium after $24 \mathrm{~h}$ of incubation (Figure 3). Growth of E. coli mastitis isolates incubated with $\mathrm{Fe}$ replenished medium plus IgG was greater than in Fedeplete medium plus IgG $(P<0.05)$. However, the addition of exogenous iron did not restore the growth to that comparable in Fe-replete medium. The addition of exogenous iron increased the growth of $E$. coli mastitis isolates after 6 (Figure 3A) and $24 \mathrm{~h}$ (Figure 3C) of incubation for anti-FecA IgG and after $6 \mathrm{~h}$ (Figure 3A) of incubation for anti-J5 IgG $(P<0.05)$. The addition of exogenous iron did not increase the growth of $E$. coli mastitis isolates incubated with control $\operatorname{IgG}(P>0.05)$.

The growth of $E$. coli UT5600/pSV66 in Fe-replenished medium plus IgG was greater than growth in either Fe-deplete medium or Fe-deplete medium containing IgG. In the presence of anti-FecA and anti-J5 IgG, the addition of exogenous iron increased the growth of $E$. coli UT5600/pSV66 after 6 (Figure 4A) and $12 \mathrm{~h}$ (Figure 4B) of incubation $(P<0.05)$. The growth did not increase with the exogenous iron in the presence of control IgG after $6 \mathrm{~h}$ of incubation $(P>0.05)$ (Figure $4 \mathrm{~A}$ ); however, the growth increased after $12 \mathrm{~h}$ (Figure $4 \mathrm{~B})$ and $24 \mathrm{~h}$ of incubation $(P<0.05)$ (Figure $4 \mathrm{C}$ ). Growth of $E$. coli UT5600/pSV66 in Fe-replete medium was greater than in Fe-replenished medium, with or without IgG.

\section{DISCUSSION}

Vaccinating cows with FecA had little effect on the growth inhibitory properties of IgG toward $E$. coli mas- 
A

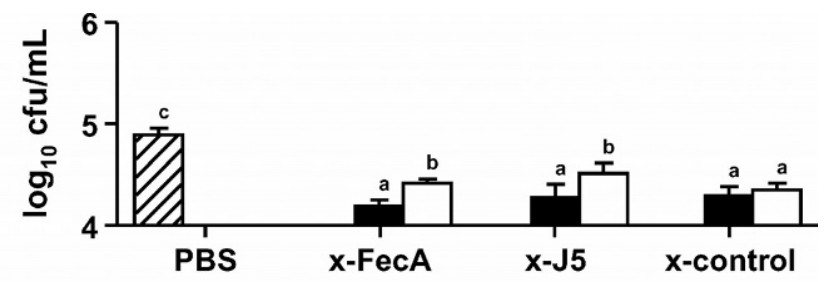

B

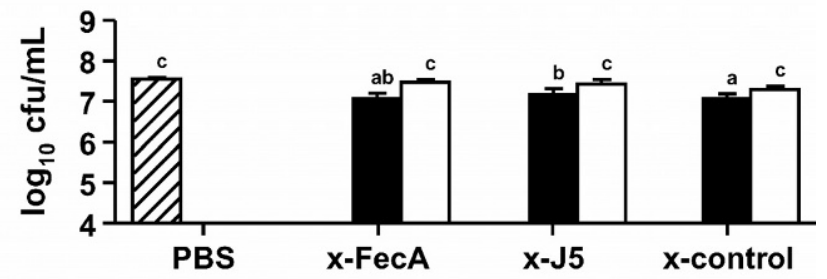

C

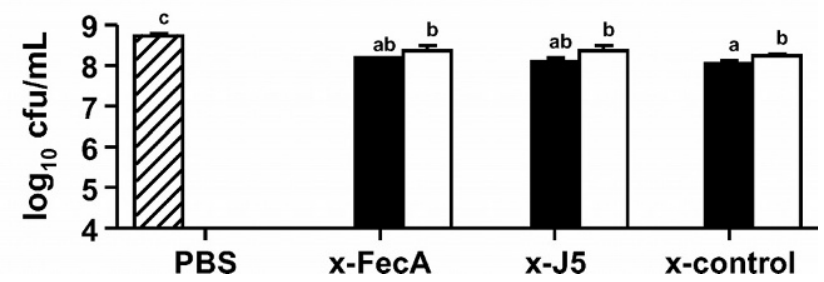

Figure 3. Mean colony-forming units $\left(\log _{10} \mathrm{cfu} / \mathrm{ml}\right)$ for Escherichia coli field isolates $(\mathrm{n}=14)$ at 6 (graph $\mathrm{A}), 12$ (graph B), and $24 \mathrm{~h}$ of incubation (graph $\mathrm{C}$ ) in chemically defined medium alone (PBS), or containing $4 \mathrm{mg} / \mathrm{mL}$ of either anti-FecA IgG (FecA), anti-E. coli J5 IgG (J5), or control IgG (control). Hashed bar represents Fe-replenished medium without IgG, solid bar represents Fe-deplete medium plus IgG, and open bar represents Fe-replenished medium plus IgG. Dispersion bars represent standard error of the mean. ${ }^{\mathrm{a}, \mathrm{b}, \mathrm{c}}$ Means within a graph with differing superscripts differ $(P<0.05)$.

titis isolates cultured in Fe-deplete media. Iron depletion of media decreased the growth responses of $E$. coli. The addition of bovine IgG from colostrum further decreased the growth compared with iron depletion alone. However, the growth of $E$. coli did not differ among IgG sources or between concentrations tested. Escherichia coli mastitis isolates grown under the experimental conditions expressed FecA, suggesting that $E$. coli utilized the ferric citrate transport system to acquire iron in the assay. Although purified IgG from FecA immunized cows reduced iron uptake of $E$. coli (Takemura et al., 2003), the mastitis isolates replicated in the presence of anti-FecA IgG in the current study. Escherichia coli can utilize multiple iron transport systems under iron restricted conditions (Braun et al., 1998), therefore the isolates may have utilized iron transport systems other than the ferric citrate transport system compromised by anti-FecA binding. Escherichia coli isolated from bovine IMI commonly express FepA and utilize the enterobactin system for iron acquisition (Lin et al., 1998b). Frost and Rosenberg (1973) reported E. coli may express FecA and FepA simultaneously, and the ferric
A

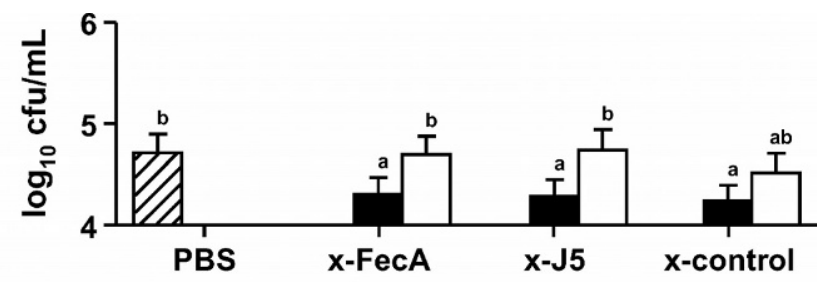

B

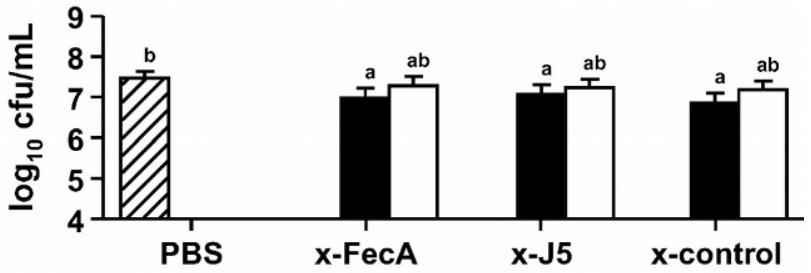

C

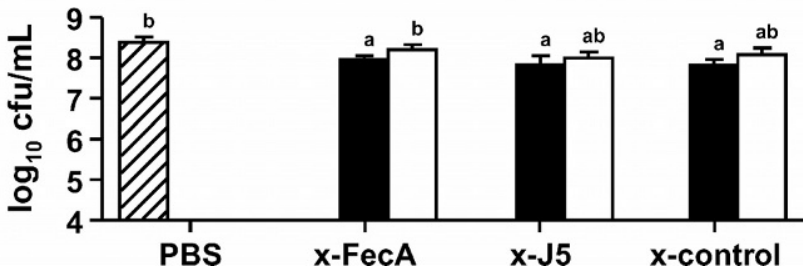

Figure 4. Mean colony-forming units $\left(\log _{10} \mathrm{cfu} / \mathrm{ml}\right)$ for Escherichia coli UT5600/pSV66 at 6 (graph A), 12 (graph B), and $24 \mathrm{~h}$ of incubation (graph C) in chemically defined medium alone (PBS), or containing $4 \mathrm{mg} / \mathrm{mL}$ of either anti-FecA IgG (FecA), anti- $E$. coli J5 IgG (J5), or control IgG (control). Hashed bar represents Fe-replenished medium without IgG, solid bar represents Fe-deplete medium plus IgG, and open bar represents Fe-replenished medium plus IgG. Dispersion bars represent standard error of the mean. ${ }^{a, b, c}$ Means within a graph with differing superscripts differ $(P<0.05)$. citrate-mediated system appeared to function as an auxiliary Fe-scavenging mechanism.

In contrast to $E$. coli mastitis isolates, E. coli UT5600/ pVS66 (Lin et al., 1999b) lacks the gene fepA and does not harbor the ColV plasmid. Therefore, E. coli UT5600/ pVS66 does not utilize the FepA and enterobactin system. The growth of $E$. coli UT5600/pSV66 was reduced after 6 and $12 \mathrm{~h}$ of incubation in the presence of antiFecA IgG, and after $6 \mathrm{~h}$ of incubation in the presence of anti-J5 IgG. Iron is an essential nutrient for bacterial survival and multiplication, and a previous study revealed that anti-FecA IgG greatly reduced the iron uptake of E. coli UT5600/pVS66 (Takemura et al., 2003). The effect of anti-FecA IgG inhibiting iron uptake apparently reduced the growth of $E$. coli UT5600/pSV66 in the present study. After $6 \mathrm{~h}$ of incubation, the addition of exogenous iron increased the growth of $E$. coli UT5600/pSV66 in the presence of anti-FecA and antiJ5 IgG, but not control IgG. The growth enhancement of exogenous iron found in the current study suggests specific iron-related growth inhibitory effects of IgG from FecA and $E$. coli J5 immunized cows. 
The growth enhancement effect of exogenous iron was greater for $E$. coli UT5600/pSV66 compared with that observed for $E$. coli mastitis isolates. Bacterial counts increased from $10^{4} \mathrm{cfu} / \mathrm{mL}$ after $6 \mathrm{~h}$ of incubation to $10^{7}$ and $10^{8} \mathrm{cfu} / \mathrm{mL}$ after 12 and $24 \mathrm{~h}$ of incubation, respectively. A single bacterial cell contains approximately $10^{5}$ iron ions (Matzanke et al., 1991), therefore $10^{7} \mathrm{cfu} / \mathrm{mL}$ E. coli may require $10^{12}$ iron ions per generation. Escherichia coli needed to obtain iron from the ferric complexes $\mathrm{Fe}-\alpha$ - $\alpha$ "-dipyridyl and $\mathrm{Fe}$-citrate in the current assay. Escherichia coli mastitis isolates likely utilized enterobactin that possesses high affinity toward $\mathrm{Fe}^{3+}$ with a stability constant of $10^{37.6}$ (Harris et al., 1979). Therefore, even in Fe-deplete BSB, E. coli mastitis isolates could acquire a sufficient amount of iron required to support growth. However, E. coli UT5600/pSV66 probably utilized ferric citrate as the sole high affinity iron acquisition system. Ferric citrate has a stability constant of $10^{25}$ for the unprotonated form and $10^{12}$ for the protonated form compared with $10^{16 . .3}$ for $\alpha$ - $\alpha^{\prime \prime}$-dipyridyl (Sillen, 1964). Thus, the addition of exogenous iron forced the equilibrium favor to ferric citrate compounds that enhanced the growth of E. coli UT5600/pSV66.

Immunoglobulin $\mathrm{G}$ from colostrum of unvaccinated cows had similar growth inhibitory effects on $E$. coli as $\mathrm{IgG}$ from $\mathrm{FecA}$ and $E$. coli $\mathrm{J} 5$ vaccinated cows. An earlier study had revealed that immunoglobulin from unvaccinated cows had a growth inhibitory effect on $E$. coli mastitis isolates cultured in Fe-deplete media (Todhunter et al., 1991b). Vaccination increased titers against FecA in the present study, but apparently this increase in specific antibody did not enhance the growth inhibitory effects over constitutive antibody in control cows. In contrast, IgG from the FecA vaccinated cows inhibited iron uptake, wheras IgG unvaccinated cows had minimal effect on iron uptake (Takemura et al., 2003). These trials suggest antibody response from FecA vaccinated cows may alter iron uptake in an in vitro assay, but have minimal effect on bacterial growth in Fe-deplete studies and clinical mastitis following intramammary challenge with Escherichia coli 727 (Takemura et al., 2002).

\section{REFERENCES}

Braun, V., K. Hantke, and W. Koster. 1998. Bacterial iron transport: mechanisms, genetics, and regulation. Met. Ions Biol. Syst. 35:67-145.
Byers, B. R., and J. E. Arceneaux. 1998. Microbial iron transport: Iron acquisition by pathogenic microorganisms. Met. Ions Biol. Syst. 35:37-66.

Frost, G. E., and H. Rosenberg. 1973. The inducible citrate-dependent iron transport system in Escherichia coli K12. Biochim. Biophys. Acta 330:90-101.

Harris, W. R., C. J. Corrano, S. R. Cooper, S. R. Sofen, and K. N. Raymond. 1979. Coordination chemistry of microbial iron transport compounds. 19. Stability constants and electrochemical behaviour of ferric enterobactin and model complexes. J. Am. Chem. Soc. 101:6097-6104.

Hussein, S., K. Hantke, and V. Braun. 1981. Citrate-dependent iron transport system in Escherichia coli K-12. Eur. J. Biochem. 117:431-437.

Lin, J., J. S. Hogan, and K. L. Smith. 1998a. Inhibition of in vitro growth of coliform bacteria by a monoclonal antibody directed against ferric enterobactin receptor FepA. J. Dairy Sci. 81:1267-1274.

Lin, J., J. S. Hogan, and K. L. Smith. 1999a. Antigenic homology of the inducible ferric citrate receptor (FecA) of coliform bacteria isolated from herds with naturally occurring bovine intramammary infections. Clin. Diagn. Lab. Immunol. 6:966-969.

Lin, J., J. S. Hogan, and K. L. Smith. 1999b. Growth responses of coliform bacteria to purified immunoglobulin $\mathrm{G}$ from cows immunized with ferric enterobactin receptor FepA. J. Dairy Sci. 82:86-92.

Lin, J., J. S. Hogan, M. Aslam, and K. L. Smith. 1998b. Immunization of cows with ferric enterobactin receptor from coliform bacteria. J. Dairy Sci. 81:2151-2158.

McDonald, J. S., and A. J. Anderson. 1981. Experimental intramammary infection of the dry cow with Escherichia coli during the nonlactating period. Am. J. Vet. Res. 42:229-231.

Matzanke, B. F., I. Berner, E. Bill, A. X. Trautwein, and G. Winkelmann. 1991. Transport and utilization of ferrioxamine-E-bound iron in Erwinia herbicola (Pantoea agglomerans). Biol. Met. 4:181-185.

Murphy, C. K., V. I. Kalve, and P. E. Klebba. 1990. Surface topology of the Escherichia coli K-12 ferric enterobactin receptor. J. Bacteriol. 172:2736-2746.

SAS User's Guide: Statistics. 1999. SAS Inst. Inc. Cary, NC. Sillen, L. G. 1964. Stability Constants of Metal-Ion Complexes. The Chemical Society, London, UK.

Takemura, K., J. S. Hogan, and K. L. Smith. 2003. Effect of immunoglobulin $\mathrm{G}$ from cows immunized with ferric citrate receptor (FecA) on iron uptake by Escherichia coli. J. Dairy Sci. 86:133137.

Takemura, K., J. S. Hogan, J. Lin, and K. L. Smith. 2002. Efficacy of immunization with ferric citrate receptor FecA from Escherichia coli on induced coliform mastitis. J. Dairy Sci. 85:774-781.

Todhunter, D. A., K. L. Smith, J. S. Hogan, and P. S. Schoenberger. 1991a. Gram-negative bacterial infections of the mammary gland in cows. Am. J. Vet. Res. 52:184-188.

Todhunter, D. A., K. L. Smith, and J. S. Hogan. 1991b. Antibodies to iron-regulated outer membrane proteins of coliform bacteria isolated from bovine intramammary infections. Vet. Immunol. Immunopathol. 28:107-115.

Weinberg, E. D. 1995. Acquisition of iron and other nutrients in vivo. Pages 79-93 in Virulence Mechanisms of Bacterial Pathogens. J. A. Roth, C. A. Bolin, K. A. Brogen, F. C. Minion, and M. J. Wannemuehler, eds. American Society for Microbiology, Washington, DC. 